\title{
Prediction of Doses Biologically Active Ultraviolet Solar Radiation from Measurements of Global Solar Radiation
}

\author{
Samy A. Khalil ${ }^{1 *}$, U. Ali Rahoma ${ }^{1}$, A.A.Hassan ${ }^{1}$, A. M. Shaffie ${ }^{2}$ \\ ${ }^{I}$ National Research Institute of Astronomy and Geophysics, Solar and Space Department, Helwan, Cairo, \\ Egypt, \\ ${ }^{2}$ Egyptian Meteorological Authority (EMA) Cairo, Egypt.
}

*Corresponding Authors: Samy A. Khalil, National Research Institute of Astronomy and Geophysics, Solar and Space Department, Helwan, Cairo, Egypt,

\begin{abstract}
The main objective of this research, estimated of mean seasonal variations doses biologically active of UV-Bm solar radiation from global broadband solar irradiance over Egypt. The measurements of global solar radiation $(G)$ and biologically effective erythematic radiation $(E E R)$ incident on a horizontal surface during the period time 1985 - 2015 at Cairo, Egypt are discussed. The monthly mean variation of slant ozone $Z$ and $U V-B m$ transmission $K t U V-B$ at the present work are found. The comparison between the two variables slant ozone $Z$ and $U V-B m$ transmission $K t U V-B$ are found. The seasonal statistical values of regression equations as the slopes $(\beta)$, intercepts $(\alpha)$ and the standard errors $(S E)$ for the fitted lines are done. The minimum slope occurs in winter, indicating that the percentage reduction in EER at higher slant ozone $Z$ is larger than $G$. The variations of the slopes $(\beta)$ during the year ranges from a minimum of 0.2867 in winter to a maximum of 0.3253 in summer, the intercepts also show their minimum and maximum values in cold humid and hot dry months. The temporal variability of the percentage ratio of the total hourly mean daily erythema to total hourly mean daily broadband solar global irradiation $(E E R / G)$ is presented. The estimated values of $U V$-Best solar radiation are a good agreement with the measured values of the $U V-B m$ solar radiation. The difference between the estimated and measured values of $U V$-B solar radiation varies from 3.1 to $4.25 \%$.
\end{abstract}

Keywords: UV-B solar radiation; stratospheric ozone; global solar radiation; solar zenith angle.

\section{INTRODUCTION}

The ghastly scope of sun based radiation relating to frequencies $\lambda<400 \mathrm{~nm}$, is called bright (UV). The bright is subdivided into three frequency band locales: the UV-A $(315-400 \mathrm{~nm})$ which is gotten at earth's surface, the UV-B $(280-315 \mathrm{~nm})$ which is halfway consumed by ozone or dispersed in the climate and UVC $(<290 \mathrm{~nm})$ which is possibly the most hazardous as it has the most elevated vitality levels, however this frequency band area is totally consumed by stratospheric ozone and oxygen above about $30 \mathrm{~km}$. Stratospheric ozone is known to be the most significant environmental factor deciding clear sky UV-B radiation arriving at the Earth's surface. The potential increment of UV-B presentation is the reason for mounting worry about the ozone layer. There are, be that as it may, different impacts that impact the UV brilliant vitality move: overcast spread, pressurized canned products, tropospheric ozone, and different vaporous toxins. The connections between different marvels occurring in the environment are perplexing. Along these lines, ground based UV estimations are important to investigate climatic changes and resultant impacts on the biosphere. The information on sun powered UV radiation arriving at the Earth's surface has an extraordinary intrigue due to its huge job in climatic and natural procedures. The UV-B sun based radiation $(280-315 \mathrm{~nm})$ speaks to $\approx$ $0.5 \%$ of the all-out radiation arriving at the earth surface, and it is significant for the Earth-living frameworks since it is a radiation of high vitality. UV-B irradiance on the Earth surface relies upon land factors, for example, scope, stature, earth-sun separation, and sunlight based peak edge (SZA), and so forth. The impact of these elements can be assessed utilizing distinctive radiative models. Anyway UV-B sunlight based radiation relies upon air parameters like ozone, mists and pressurized canned products. Ozone is the gas that ingests UVC and some UV-B sun powered radiation and the impact of the complete ozone segment was remembered for every single radiative model. Mists are 
another weakening element of UV-B radiation and because of their arbitrary nature they are hard to show. Aerosol is the factor that influences radiation levels under cloudless sky conditions [1-3].

During the most recent two decades, worries about the power levels of UV-B sun based radiation arriving at the ground have expanded due to the stratospheric ozone consumption and the emotional increment in the quantity of skin malignant growths in the populace. The UV sun oriented vitality at the ground fluctuates extraordinarily with neighborhood time, scope and season, fundamentally due to the changing rise of the sun in the sky. The ozone assumes a job of shield around the Earth shielding us from bright radiation. The UV-B radiation just speaks to 5\% of the UV radiation [4], the UV-B is imperative to individuals since it can create various ailments [5]. Often the naturally successful irradiance is given as UV record (UVI). UVI is a dimensionless amount and one unit is proportional to $25 \mathrm{mWm}^{-2}$ of erythematic radiation. The Earth's climate fundamentally changes the approaching sun oriented radiation through the retention and dispersing process by gases, dust particles and other biosphere constituents of human and common exercises, there is clear straight connection between UV-B and worldwide sun powered radiation, especially in the district of moderate to low worldwide irradiance, which empowers estimation of UV-B motion in tropical/central zones where offices for UV-B estimations are not accessible, yet worldwide sun oriented radiation transition information exist $[3,6-9]$.

The connection between the all-out ozone and unearthly UV irradiance from Brewer spectrophotometer perceptions and its utilization for deduction of complete ozone from UV estimations has been the subject of [10]. The most critical effect on got clear sky UV-B is that subsequent from variety in air ozone [11]. A great part of the unsafe UV-B is consumed by stratospheric ozone, albeit descending patterns saw in absolute section ozone, especially at high scopes, and to a lesser degree at midlatitudes, suggest huge increment in the surface UV presentation [12]. The anticorrelation between absolute section ozone and UV radiation is an unpredictable capacity of numerous factors, as: sun based apex edge, sunlight based rise, overcast spread, airborne and vertical profile of ozone. The constriction of UV-B radiation by mists is regularly bigger than some other barometrical parameter; anyway it is frequently just approximated by demonstrating the impact of month to month or occasionally found the middle value of cloud sums [13-17]. Groundbased perceptions can assume a significant job in improving the comprehension of a portion of these impacts [18].

The beneficial impacts of UV-A and UV-B radiation on people, the biological system, creatures, plants, and materials have been tended to by numerous examiners [3, 19-27]. The investigation of the proportions of organic UV to G have gotten a considerable consideration in the previous barely any years so connections of this sort have been proposed by various agents with estimations from Kuwait [28], Dharan [29], Edmonton [30], Saudi Arabia [31], Valencia [32, 33], Spain [34,35], Egypt [36], France [37], Iran [38] and Switzerland [39]. In another examination a relationship was set up between a 18-month record of day by day UV-B and full band (300-3000 $\mathrm{nm}$ ) sun oriented radiation in Sutton (Britain) [40]. They proposed a direct connection between the proportion of vitality in the two wavebands and the cosine of pinnacle point at early afternoon which empowers the UV-B illumination to be assessed from full band $(\mathrm{G})$ sunlight based radiation. Utilizing a progression of estimations including bright (UV) $(280-320 \mathrm{~nm})$, UV-A $(320-400 \mathrm{~nm})$, and broadband worldwide (250-2800 nm) produced using June 1998 to August 2001 at a station in Kwangju, South Korea , Ogunjobi and Kim [41] inferred that the proportion of absolute UV (280-400 nm) to broadband radiation is about $7.7 \%$ for all-sky conditions. The proportion of the bright to worldwide radiation (UV/G) was additionally determined by [18], for two urban communities in Egypt and contrasted and different locales in the Middle Eastern Promontory. Some portion of this examination was utilized before to assess the expectation of clear-sky organically viable erythematic radiation from worldwide sun powered radiation [3]. Right now, estimation of hourly mean day by day erythema (EER) from hourly mean every day broadband $(G)$ in urban areas has once in a while been contemplated, the fundamental point of this examination is to build up an exact connection between absolute sun based radiation $(\mathrm{G})$ and viable erythema radiation (EER), which empowers the estimation of the day by day coordinated EER from effectively accessible broadband (250-2800 nm) G information in such atmospheres, and the information right now acquired from the Meteorological Authority of Egypt. 


\section{THEORY OF METHODOLOGY AND MODEL VARIABLES}

The extraterrestrial sun oriented radiation on a flat surface was determined from the condition $[15,42$, and 43]. The hourly estimation of hemispherical transmittance ( $\mathrm{Kt}=\mathrm{G} / \mathrm{Gext}$.) is characterized as the proportion of worldwide sun based radiation on an even surface at the ground $(\mathrm{G})$ to the comparing amount outside the World's climate (Gext.) [44].

The UV-B estimations of sun oriented radiation were changed over into UVER (sunlight based bright erythematic irradiance) values by methods for transformation factors, (Diffey factor) gave by the producer [45,46], and from them UVI (bright records) hourly qualities were assessed [47]. These UVI results have been considered as estimated esteems and spoke to by (UVI) (Center East carrier's esteems). UVI values have additionally been acquired from ghastly determined weighted by the erythema activity range, they are spoken to by (UVI) demonstrate and can be gotten by the accompanying articulation:

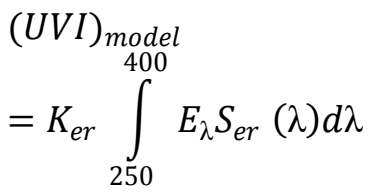

Where $E_{\lambda}$ is the solar spectral irradianceexpressed in $\left(\mathrm{Wm}^{-2} \mathrm{~nm}^{-1}\right)$ at wavelength $\lambda$ and $d \lambda$ is the wavelength interval used in the summation, $S_{e r}(\lambda)$ is the erythema reference action spectrum, and $K_{e r}$ is a constant equal to $40 \mathrm{~m}^{2} / \mathrm{W}[48,49]$.

The actual ozone amount crossed through by the solar radiation in the atmosphere is the slant total ozone column, (Dobson, DU). The Dobson unit (DU) is a unit of measurement of the amount of a trace gas in a vertical column through the Earth's atmosphere. It originated, and continues to be primarily used in respect to, atmosphere ozone, whose total column amount, usually termed "total ozone", and sometimes "column abundance", is dominated by the high concentrations of ozone in the stratospheric ozone layer $[50,51]$ defined as:

$Z$

$=\frac{T O C}{\cos (S Z A)}$

Where TOC is the total ozone column recorded at the solar zenith angle (SZA), this expression is only valid for the direct solar irradiance. However, it can be used as a good approximation for the global solar irradiance. However, the largest part of ozone absorption takes place at high altitudes, before the scattering process by aerosol and cloud [52].

Total ozone column (TOC) is defined as being equal to the amount of ozone contained in a vertical column of base $1 \mathrm{~cm}^{2}$ at standard pressure and temperature. It can be expressed in units of pressure, typically about 0.3 atmosphere centimeters. The milli atmosphere centimeter $(\mathrm{m}$ atm. $\mathrm{cm})$ (commonly called the Dobson Unit corresponding to an average atmospheric concentration of approximately one part per billion by volume ( $1 \mathrm{ppbv})$ of ozone, is most frequently used.

In analogue with the broadband and UV cases, the UV-B hemispherical transmittance can be defining in the following way $[53,54]$.

$\mathrm{Kt}_{\mathrm{UV}}=\frac{U V-B}{U V-\text { Bext }}$

Where UV-B $\mathrm{B}_{\mathrm{ext}}$.is the extraterrestrial UV-B radiation value on a horizontal surface it is given by:

UV-Bext. $=\mathrm{I}_{\text {SCUV-B }}(12 / \pi) \mathrm{E}_{0} \int_{w 2}^{w 1} \sin (\theta) d w$

Where $(\theta)$ is the solar elevation angle, $E_{0}$ is the correction factor for the eccentricity of the Earth's orbit, $w_{\mathrm{i}}$ ( $\mathrm{i}=1$ and 2 ) is the solar our angle at the beginning of period and at the end of period, respectively, and $\mathrm{I}_{\mathrm{SCUV}-\mathrm{B}}$ is the UV-B solar constant $\left(21.51 \mathrm{Wm}^{-2}\right)[6,15,55]$.

The relationship between the effective erythematic radiation (EER) and global solar radiation $(\mathrm{G})$ as following equation (10) and several investigations $[9,15,26,56]$, the linear relationship: 


$$
E E R=\beta G+\alpha
$$

Where EER is the daily erythem irradiance, $G$ is the daily broadband global radiation, $\beta$ is the slope of the linear relation, and $\alpha$ is the intercept. Under clear-sky conditions, SZA and TOC appear to be the major determinant affecting on the ratio of EER and G. Inverse relation is known between the ozone density in the atmosphere and the amount of UV reaching the earth's surface [57].

Other variables affecting by day-to-day fluctuation (aerosol, water vapor, air pressure) have smaller influence than SZA and TOC. In order to remove the ozone dependency from the relationship, the values of $\beta$ were normalized to the monthly mean values of the total ozone column (TOC)by using the following factor [58]:

$$
\mathrm{Co}_{3}=\exp \left[-\mathrm{ko}_{3}\left(\Delta \mathrm{O}_{3}\right) m\right]
$$

Where: $\mathrm{Ko}_{3}$ is the mean ozone absorption coefficient for the wavelengths $300-316 \mathrm{~nm}$ and takes the value of $3.546(\mathrm{~atm} \mathrm{~cm})^{-1}, \Delta \mathrm{O}_{3}$ is the difference between the monthly average TOC value and the TOC mean value in the period and $\mathrm{m}$ is the monthly mean air mass at noon.

\section{RESULTS AND DISCUSSION}

Exposure data for Cairo, Egyptsites (1985-2015) is of value in developing biological dose- response relationships. The exposure of differentanatomical sites to solar UVR depends not onlyon ambient UVR and the atmospheric parameter (air, temperature and relative humidity) of siteswith respect to the global solar radiation, but also on industrial behaviour. The most exposed skin surfaces, such as the nose, tops of the ears and forehead,have levels of UVB exposure that range up to oneorder of magnitude relative to that of the lesser exposed areas. Table1: shows the mean yearly values of $\mathrm{G}($ total), and $\mathrm{Kt}(\mathrm{G})$ through the interval from years of 1985 to 2015 total are given by; $\mathrm{G}($ total $)=$ $5.127 \pm 0.04475\left(\mathrm{Kwh} / \mathrm{m}^{2} /\right.$ day $)$ and $\mathrm{Kt}(\mathrm{G})$ total $=0.5865 \pm 0.004486$. The mean daily values of $\mathrm{G}$ (annually as the daily mean) is $5.354 \pm 1.779 \quad\left(\mathrm{KWh} / \mathrm{m}^{2} /\right.$ day), and $\mathrm{G}$ (annually as the monthly mean $)=5.127 \pm 0.0447\left(\mathrm{KWh} / \mathrm{m}^{2} /\right.$ day $)$ but the $\mathrm{Kt}(\mathrm{G})$ annually as the daily mean $=0.586$ \pm 0.0447 . The standard deviation (SD) of $\mathrm{G}(\mathrm{total})$, and $\mathrm{Kt}(\mathrm{G})$ through the interval from years of 1985 to 2015 ; which gives for $\mathrm{SD}=9.869-0.004 *(1985-2015)$, residual sum of squares $=0.204535$, Coefficient of determination, R-sq. $=0.163075$, and SD (total) $=1.852 \pm 0.090\left(\mathrm{Kwh} / \mathrm{m}^{2} /\right.$ day $)$. Table 2: shows the mean yearly values of UV-B (annually as the daily mean), and Kt (UV-B) (annually as the daily mean), through the interval from years of 1985 to 2015 total is given by; UV-B (annually as the daily mean $)=2.36 \pm 0.11\left(\mathrm{Wh} / \mathrm{m}^{2} / \mathrm{day}\right), \quad$ and Kt UV-B (annually as the daily mean $)=$ $0.105 \pm 0.005$. The standard deviation of UV-B, and Kt UV-B through the interval from years of 1985 to 2015; which gives for SD UV-B is 0.11 0.004 , and Kt (UV- B) is 0.0051. Also we notice that the maximum values of the above parameters occur around the summer months, while the minimum values in winter months. But the values of these variables are clear that in the spring and autumn months fall between the values of the summer and winter months, the estimated values of UV-Bmes. solar radiation a good agreement with the measured values of the UVBm solar radiation, the difference between the estimated and measured values of UV-Bmes. solar radiation varies from $3.1 \%$ to $4.25 \%$. The average monthly UV-Bm. clearness index (KtUV$\mathrm{B}$ ) is less thanthecorresponding values for global radiation kt, where the value of ktis equal to the value of global solar radiation $(\mathrm{G})$ dividing by the value of extra-terrestrial global solar radiation $\mathrm{G}_{\mathrm{ext}}$. However, $\mathrm{Kt}(\mathrm{UV}-\mathrm{B})$ values vary from 0.068 to 0.146 . This behavior is due to the extremely high attenuation of UV-Bmes. radiation by stratospheric ozone and scattering phenomena.

Table (3): shows the meteorological parameters (relative humidity; the total number of clear sky days; the total number of dusty days and Total Column Ozone (Dobson) (TOC)) have also been recorded during the period time from 1985 to 2015 in the present study. To calculate the monthly mean values from the daily data, the work of Sabziparvar and Shetaee [51] was adapted. A dimensionless empirical relationship in the form of EER/G was developed, which can allow for the estimation of EER radiation from commonly measured global solar radiation $(\mathrm{G})$. The daily clearsky EER radiation can be estimated from broadband $\mathrm{G}$ data. 
Prediction of Doses Biologically Active Ultraviolet Solar Radiation from Measurements of Global Solar Radiation

Table1. mean yearly values of $G($ total), and $K t(G)$ through the interval from years of 1985 to 2015.

\begin{tabular}{|l|l|l|l|l|l|l|}
\hline & $\begin{array}{l}\text { G (annually) } \\
\left(\mathrm{KWh} / \mathrm{m}^{2} / \text { day }\right)\end{array}$ & Year & $\mathrm{Kt}(\mathrm{G})$ & Year & $\begin{array}{l}\text { SD }(\mathrm{G}) \\
\left(\mathrm{KWh} / \mathrm{m}^{2} / \text { day }\right)\end{array}$ & Year \\
\hline $\begin{array}{l}\text { Number of } \\
\text { values }\end{array}$ & 31 & & 31 & & 31 & \\
\hline Minimum & 5.04 & 1988 & 0.578 & 1988 & 1.7075 & 2005 \\
\hline Maximum & 5.2 & 1996 & 0.598 & 1996 & 2.0469 & 1993 \\
\hline Range & 0.16 & & 0.02 & & 0.3394 & \\
\hline Mean & 5.127 & & 0.5865 & & 1.852 & \\
\hline SD & 0.0447 & & 0.0045 & & 0.090 & \\
\hline
\end{tabular}

Table2. shows the standard deviation of $U V-B(W / m 2 /$ day), and $K t U V-B$ through the interval from years of 1985 to 2015.

\begin{tabular}{|c|c|c|c|c|c|c|}
\hline & $\begin{array}{c}\text { UV-B } \\
\text { (W/m2/day) }\end{array}$ & Year & Kt(UV-B) & Year & SD (W/m2/day) & Year \\
\hline Number of values & 31 & & 31 & & 31 & \\
\hline Minimum & 2.083 & 1993 & 0.092 & 1989 & 0.611 & 1989 \\
\hline Maximum & 2.528 & 1986, & 0.113 & 2004, & 0.861 & 1986 \\
& & 2003, & & 2010 & & \\
& & 2004, & & & & \\
\hline Range & 0.444 & & 0.021 & & 0.25 & \\
\hline Mean & 2.363 & & 0.1049 & & 0.743 & \\
\hline SD & 0.1134 & & 0.0051 & & & \\
\hline
\end{tabular}

Table3. shows the monthly means of meteorological parameters at Cairo during the period time 1985 to 2015.

\begin{tabular}{|ccccc|}
\hline month & $\begin{array}{c}\text { Total Column } \\
\text { Ozone (Dobson) (TOC) }\end{array}$ & $\begin{array}{c}\text { Total Number of } \\
\text { Clear sky Days (NCD) }\end{array}$ & $\begin{array}{c}\text { Total Number } \\
\text { of Dust days (NDD) }\end{array}$ & $\begin{array}{c}\text { Relative } \\
\text { Humidity (RH \%) }\end{array}$ \\
\hline Mean & 297.28 & 20.75 & 2.64 & 41.3 \\
SD & 15.508 & 5.808 & 0.71 & 11.6 \\
\hline
\end{tabular}

Figure 1, shows the monthly mean values, maximum, minimum and seasonally of slant ozone (Z) and Figure 2, clearness index of UVB solar radiation $\left(\mathrm{Kt}_{\mathrm{UVB}}\right)$ in the present study during the period time from 1985 to 2015. Figures 1\&2; can explain the different values of slant ozone during the period time in the present research. Firstly, the comparison between the maximum and minimum values of $(\mathrm{Z})$ and $\left(\mathrm{Kt}_{\mathrm{UVB}}\right)$ are at all months from January to December during the period time from 1985 to 2015. In January month the maximum value of $(Z)$ is equal 439DU occur during the year 1998, while the minimum value is 385DU during the year 1993, and the maximum value is 394 DU during 1992 in February month and minimum value during 1995 is $369 \mathrm{Du}$. For March month the maximum value is equal $358 \mathrm{Du}$ in 2003 year and the minimum is $337 \mathrm{Du}$ in 2015 year, while in April, May and June months the maximum values of $(\mathrm{Z})$ are 322, 307 and $288 \mathrm{Du}$ in the year 2015 respectively and minimum values are 288, 281 and 271 Du respectively occur in the year 2013. But in July, August, September months are 295, 303 and 329Du in years 2013, 2012 and1992 respectively, while the minimum values of $(Z)$ in the same months are 279, 276 and 297Du at years 2015, 1988 and 2015 respectively, also during the months October, November and December, the maximum values of $(\mathrm{Z})$ are 358, 374 and 402Du through the years 1986, 1988 and 1989 respectively, and the minimum values of $(\mathrm{Z})$ are 321, 339 and 370Du about the years 2015, 1989 and 2015 respectively. Also from this table, we notice that the maximum and minimum values of seasonal variations of the slant ozone $(\mathrm{Z})$ in the present study. The maximum values are 412, 329, 295 and 354 in winter, spring, summer, and autumn respectively, while the minimum values is $375,302,275$ and 343 in winter, spring, summer, and autumn respectively.

The comparison between the maximum and the minimum values of $\left(\mathrm{Kt}_{\mathrm{G}}\right)$ is from January to December during the period time from 1985 to 2015. In January month the maximum value of $\left(\mathrm{KT}_{\mathrm{G}}\right)$ is equal 0.580 occur during the year 1986, while the minimum value is 0.524 during the year 2003, and the maximum value is 0.546 during 1993 in February month and the minimum value during 1985 is 0.525 . For March month the maximum value is equal 0.590 in 1993 year and the minimum is 0.524 
in 1985 year, while in April, May and June months the maximum values of $\left(\mathrm{KT}_{\mathrm{G}}\right)$ are $0.665,0.689$ and 0.691 in years 1992, 1986 and 2003 respectively and minimum values are $0.639,0.624$ and 0.645 respectively occur in years 1998, 2008 and 2005. But in July, August, September months are 0.696, 0.652 and 0.630 in years 1994, 2012 and1986 respectively, while the minimum values of $\left(\mathrm{KT}_{\mathrm{G}}\right)$ in the same months are $0.623,0.610$ and 0.522 at years 2001, 1988 and 2006 respectively, also during the months October, November and December maximum values of $\left(\mathrm{KT}_{\mathrm{G}}\right)$ are $0.611,0.574$ and 0.550 through the years 1987, 1986 and 1986 respectively, and the minimum values of $\left(\mathrm{KT}_{\mathrm{G}}\right)$ are 0.515 , 0.509 and 0.502 about the years 2006, 2006 and 1989 respectively. Also from this table, we notice that the maximum and minimum values of seasonal variations of the clearness index $\left(\mathrm{KT}_{\mathrm{G}}\right)$ in the present study. The maximum values are $0.559,0.648,0.680$ and 0.605 in winter, spring, summer, and autumn respectively; while the minimum values are $0.517,0.596,0.626$ and 0.515 in winter, spring, summer, and autumn respectively.

The average monthly mean of slant ozone $\mathrm{Z}$ and UV-Bm transmission $\mathrm{Kt}_{\mathrm{UvB}}$ at Cairo, Egypt in the present research during the period time from 1985 to December 2015 are show in figures 1 and 2 respectively. From figure 1, we notice that the maximum values of the slant ozone (Z) occur in the winter months, while the minimum values occur in summer months, but the values of slant ozone in spring and autumn months fall between the values of winter and summer seasons during the period time from 1985 to 2015 in the present research. And we indicate from figure 2, the maximum values of $\mathrm{KT}_{\mathrm{UVB}}$ occur around the summer and spring months, while the minimum occur in winter and autumn seasons.

Figure 3: Mean values of different years for global solar radiation in Cairo, Egypt, data in the present study during the period time from 1985 to 2015. Gradual changes start from the winter months at a rate that starts from $2.5(\mathrm{Kwh} / \mathrm{m} 2 /$ day $)$ to $8(\mathrm{Kwh} / \mathrm{m} 2 /$ day $)$ gradually rises to the summer months accompanied by an increase in the air temperature and a decrease in the relative humidity as shown in figure 4. The annual rate is almost identical in the fluidity of the total solar radiation intensity with the percentage of slight changes. It is clear from figure 4 that an increase in the value of KTUV- B of winter months from 0.075 to 0.150 in contrast to the various values of relative humidity $64 \%$ until it reaches the highest value in the months of August and the lowest value $22 \%$ of relative humidity in that month.

Figure 5, shows mean values of the clearness index of $\mathrm{KT}_{\mathrm{G}}$ and $\mathrm{KT}_{\mathrm{UVB}}$ at Cairo, Egypt, and Figure 6, shows mean values of total ozone column (TOC) and KtUV- B at Cairo, Egypt. It is clear that the monthly means maximum, minimum and seasonally values of (TOC) and (KtG) in the present research during the period time from 1985 to 2015 give as shown in table 5. Figure 6 shows increase of TOC in the winter and spring months, and the decrease in the percentage of ultraviolet radiation UV-B, perhaps due to the increase in soil spread through the Khamseen winds, accompanied by a reflection of the curve with the beginning of the summer months, the passage of the autumn months, with low relative humidity, high temperature, and low rates of dust storms.

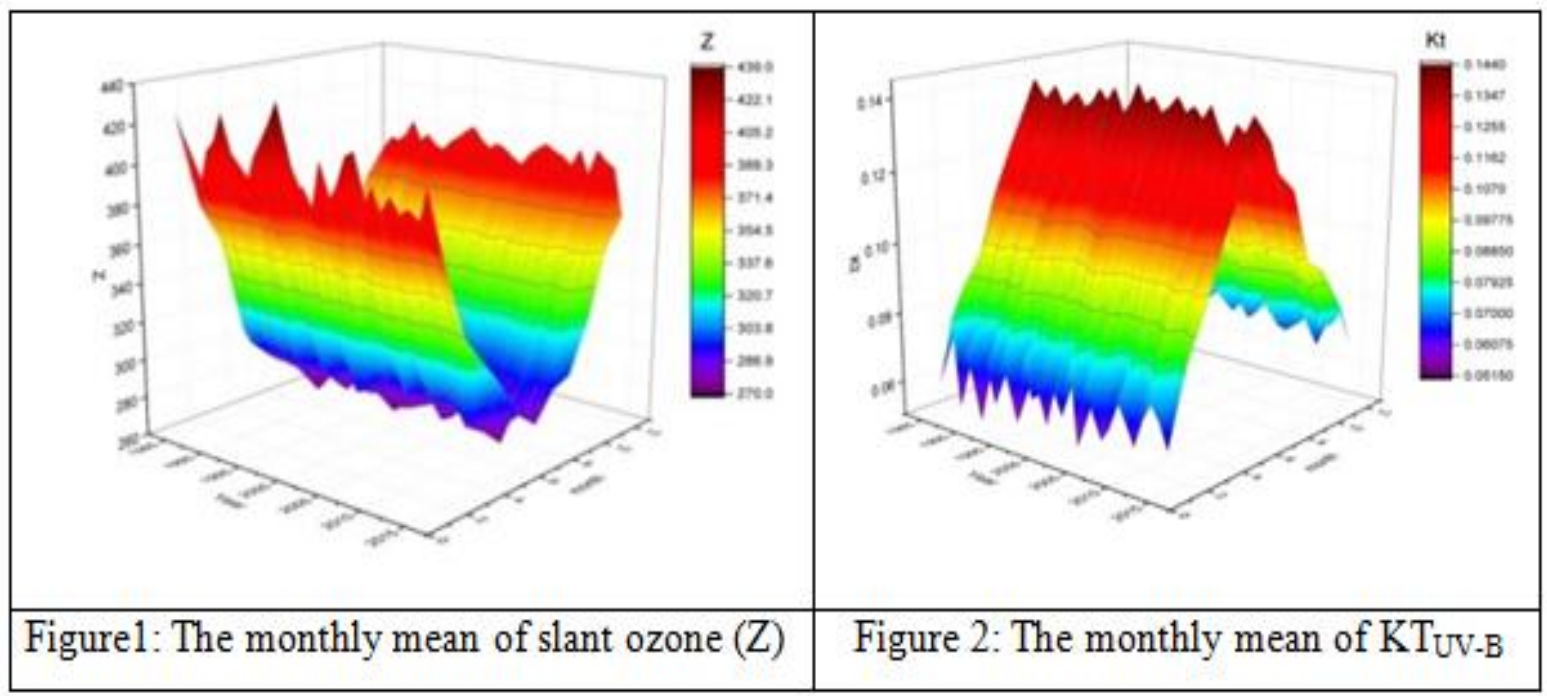


Prediction of Doses Biologically Active Ultraviolet Solar Radiation from Measurements of Global Solar Radiation



Table5. Monthly mean maximum, minimum and seasonally values of (TOC) and $(\mathrm{KtG})$ in the present research during the period time from 1985 to 2015.

\begin{tabular}{|c|c|c|c|c|c|c|}
\hline \multirow{2}{*}{ Month } & Max & Min & Max & Min & Max & Min \\
\cline { 2 - 7 } & TOC & TOC & $\mathrm{K}_{\mathrm{tG}}$ & $\mathrm{K}_{\mathrm{tG}}$ & $\mathrm{KT}_{\mathrm{UVB}}$ & $\mathrm{KT}_{\mathrm{UVB}}$ \\
\hline Winter & 412 & 375 & 0.559 & 0.517 & 0.085 & 0.066 \\
\cline { 2 - 7 } Spring & 329 & 302 & 0.648 & 0.596 & 0.15 & 0.12 \\
\cline { 2 - 7 } Summer & 295 & 275 & 0.680 & 0.626 & 0.138 & 0.13 \\
\cline { 2 - 7 } Autumn & 354 & 343 & 0.605 & 0.515 & 0.155 & 0.144 \\
\hline
\end{tabular}

Generally, from the figure 7, it is clear that the correlation between two variables KTG and KTUVB, shows the ratio of gradual increase behavior, the low values of the slant ozone column during summertime produce down UVB transmission values in this season. The monthly means of slant ozone column and UV-Bmes. transmission values show the relationship between them in a clearer way than those of daily values. The correlation between KTG and KTUVB gives us the relationship of KtUVB is $-0.065+0.29 \mathrm{Kt}(\mathrm{G})$ with Residual sum of squares $=0.000726641$ (yearly) and Coefficient of determination, R-squared $=0.0653943$. The linear correlation between KTG and KTUVB in the present study during the period from 1985 to 2015 is shown in figure 7. This correlation consists of 746 numbers of data set and a good correlation between KTG and KTUVB with the correlation coefficient $\mathrm{R} 2=0.82$ and slandered deviation $\mathrm{SD}=0.05078$, the equation gives as $\mathrm{Kt}(\mathrm{UVB})$ is $-0.065+0.29 \mathrm{Kt}(\mathrm{G})$.

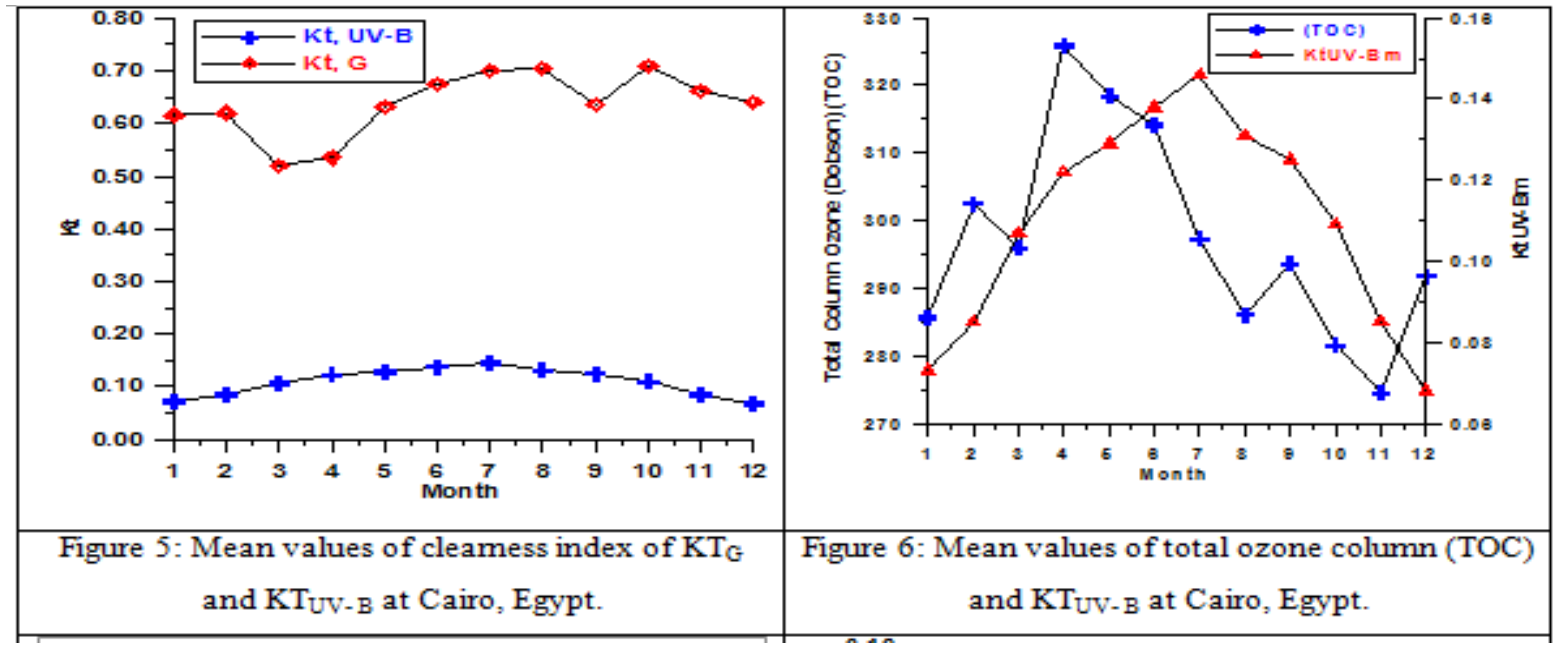




The relationship between the total ozone column and UV-B can be analyzed by considering the dimensionless parameter UVB transmission (KTUV-B) and Z slant ozone. Simultaneous variation of KTUV-B and TOC values through the period of this study was employed. Figure 9, and 11, shows the variation of monthly values for KTUV-B and TOC in all-sky conditions during the whole period of this study for Cairo. The two variables show the opposite seasonal behavior. The low values of TOC column during summertime produce high UV-B transmission values in this season. The opposite pattern is observed during the winter. The monthly average of slant ozone column and UV-B transmission values are show the relationship between them in a clearer way than those of daily values. Figure 10 illustrates the variation of the monthly average of slant ozone column and UVB transmission values. TOC transmission values are lies between 290 and 320 through the year from 1985 to 2015 , and UV-B lies between 2.2 to $2.5 \mathrm{wh} / \mathrm{m}^{2} /$ day. Can find the values of the clearness index of Cairo from the highest vale that this means that good visibility and good received for the solar radiation Although there is a good percentage of high air pollution as a result of various industries and hot weather factors, which impose an increase in the number of aerosols as the country enters the spring and will pass during the summer. As we show from figure 4 and 9 from the representation the TOC and relative humidity we can see that relative humidity play a role of the behavior of the curve of TOC. If we see that spring month during the decrease the degree of relative humidity finds that good value of TOC that case change if we reach to autumn months during the increase of relative humidity degrees. Referring to Figure 12, we find that the mean monthly values of Kt (UV-B) and air temperature $\mathrm{C}^{\circ}$ are very similar, meaning that the two variables apply to them in a large proportion with the same weather effects. As for looking at curve 11 and 13, we find that there are great similarities between the two figures mean monthly values of total ozone column (Dobson)total numbers of dust day. However, the pathogen is located between the effect of temperature andKt $(\mathrm{G})$. $\mathrm{Kt}(\mathrm{G})$ is greatly affected by weather factors such as the change in ozone.Atmospheric aerosol can modify the energy balance through scattering and absorption of light (Sokolik and Toon, 1996). The radiative effect of mineral aerosol from natural sources and disturbed soils contributes about $8 \%$ to total aerosol scattering of incoming solar radiation (Andreae, 1995). In particular, those mineral aerosol particles, which are characterized by a very large surface area, can strongly absorb the shortwave solar radiation, influencing the radiative forcing of climate (Dickerson et al., 1997), or causing a photolysis rate reduction, thus inhibiting ozone production. In fact, in the lower atmosphere, the mineral aerosol may strongly influence the balance of atmospheric trace gases, including ozone [59-61] in their modeling studies, suggested that the ozone destruction on mineral aerosol surfaces could lead to a $10 \%$ reduction of $\mathrm{O} 3$ concentrations in the dust source areas.

As presented in table (6), the variations of the slopes ( $\beta$ ) during the course of the year ranges from a minimum of 0.2867 in winter to a maximum of 0.3253 in summer. The intercepts also show their minimum and maximum values in cold humid and hot dry months respectively. This result emphasizes that the percentage reduction in the EER dose is always higher than such a reduction in $G$ when SZAs are high (i.e. winter). In addition to the seasonal relations, the following general relation was found to be reliable for estimation of daily integrated EER from global broadband solar radiation throughout the year: (12). It should be reminded that other variables (aerosol, water vapor, and haze) affecting the two wavebands by day-to-day fluctuation, have a smaller influence than the annual SZA and TCO cycles. Additionally, the disproportional effects of the surface albedo and dust aerosols on EER and G, might explain some of the contradictions observed in the linear relations. Improved correlations and less dependence on location can be achieved by using longer period data at other latitudes and all weather conditions. Dust aerosols are responsible for absorbing and scattering UV radiation. We consider the dusty days to quantify their extinction to represent the scattered fraction.

Table6. The seasonal statistical values of regression equations during the period time in the present study (1985 - 2015)

\begin{tabular}{|c|c|c|c|c|c|}
\hline Season & $\begin{array}{c}\text { Effective Erythema Radiation } \\
\text { of Equation }\left(\mathbf{K} \cdot \mathbf{m}^{-2} \cdot \mathbf{d}^{-1}\right) \\
(\mathbf{E E R}=\boldsymbol{\beta G}+\boldsymbol{\alpha})\end{array}$ & $\begin{array}{c}\text { Standard Error of } \\
\text { the slop of equation } \\
\text { SE }(\beta) \\
\end{array}$ & $\begin{array}{c}\text { Standard Error } \\
\text { of the interception } \\
\text { SE }(\alpha) \\
\end{array}$ & $\begin{array}{r}\text { Coefficient of } \\
\text { determination } \\
\left(\mathbf{R}^{2}\right)\end{array}$ & $\begin{array}{c}\text { Correction factor } \\
\text { for the removal } \\
\text { of ozone effect }\left(\mathrm{C}_{03}\right)\end{array}$ \\
\hline Winter & EER $=2.867 * 10^{-1} G-0.512$ & \pm 0.0124 & \pm 0.076 & 0.956 & 0.95 \\
\hline Spring & $\mathrm{EER}=2.986 * 10^{-1} \mathrm{G}-1.415$ & \pm 0.0167 & \pm 0.131 & 0.897 & 0.97 \\
\hline Summer & $\mathrm{EER}=3.253 * 10^{-1} \mathrm{G}-2.514$ & \pm 0.0139 & \pm 0.219 & 0.934 & 0.96 \\
\hline Autumn & $\mathrm{EER}=2.913 * 10^{-1} \mathrm{G}-2.138$ & \pm 0.0092 & \pm 0.042 & 0.974 & 0.93 \\
\hline
\end{tabular}

International Journal of Research in Environmental Science (IJRES) 


\section{CONCLUSION}

In this work, we studies the hourly monthly mean variation of slant ozone $\mathrm{Z}$ and UV-B transmission $\mathrm{K}_{\mathrm{tUV}-\mathrm{B}}$ at Cairo, Egypt during the period time from January 1985 to December 2015. The two variables show an opposite seasonal behavior, the minimum values of the slant ozone column during summer time produce high $U V-B_{\text {mes. }}$ transmission values in this season. The average hourly monthly mean of slant ozone column and UV-B transmission values shows the relationship between them in a

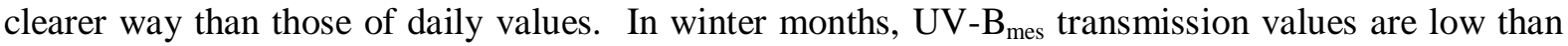
those in summer months, this due to the fact that, the slant ozone column crossed by UV- $B_{\text {mes }}$ radiation is higher in winter than in summer.

The prediction values of UV- $B_{m}$ solar radiation a good agreement with the measured values of the $\mathrm{UV}-\mathrm{B}_{\mathrm{m}}$ solar radiation, the difference between the prediction and measured values of UV- $\mathrm{B}_{\mathrm{m}}$ solar radiation varies from $1.86 \%$ to $2.94 \%$. The Seasonal Statistical values of regression equations; the slopes $(\beta)$, intercepts $(\alpha)$ and the standard errors (SE) for the fitted lines. As shown, the minimum slope occurs in winter, indicating that the percentage reduction in EER at higher SZA is larger than G. This can be explained by the increased ozone path length and higher percentage of scattering during the winter months. The variations of the slopes $(\beta)$ during the course of the year ranges from a minimum of 0.2867 in winter to a maximum of 0.3253 in summer, the intercepts also show their minimum and maximum values in cold humid and hot dry months respectively. In general, the good relation was found to be reliable for estimation of daily integrated EER from global broadband solar radiation throughout the year as following:

$$
\operatorname{EER}\left(\mathrm{Kj} \cdot \mathrm{m}^{-2} \cdot \mathrm{d}^{-1}\right)=3.114 * 10^{-1} G\left(\mathrm{Mj} \cdot \mathrm{m}^{-2} \cdot \mathrm{d}^{-1}\right)-1.863
$$

\section{REFERENCES}

[1] Palancar, G.G., B.M. Toselli, Effects of meteorology and troposphere aerosols on UV-B radiation: a 4-year study, Atmospheric Environment, 38, 2004, 2749-2757.

[2] Acosta, L.R., W.F.J.Evans, Design of the México City UV monitoring network: UV-B measurements at ground level in the urban environment. Journal of Geophysical Research 105, 2000, 5017-5026.

[3] Samy A. Khalil, A. M. Shaffie, Predication of clear-sky biologically effective erythematic radiation (EER) from global solar radiation (250-2800 nm) at Cairo, Egypt, Advances in Space Research 51, 2013, 1727 1733 .

[4] Miguel, A.H., J.Bilbao, P.Salvador, A study of UV total solar irradiation at a rural area of Spain, Solaris 2005 2nd Joint Conference, Athens (Greece), 32-3, May 2005 Edit., Hellenic Illumination Committee.

[5] Tevini, M., Molecular Biological Effects of Ultraviolet Radiation. UV-B radiation and ozone depletion: effects on humans, animals, plants, microorganism, and materials, edited by Manfred Tevini., pp. 1-17, 1993, Lewish Publishers.

[6] Iqbal M.: An introduction to solar radiation Academic Press, New York, 1983, pp 390.

[7] Ilyas M., A. pandy and S. I. S. Hassan: UV-B radiation at Penang. Atmospheric Research 51, 1999, 141152.

[8] Koronakis P.S., G. K. Sfantos , A. G. Plaiatsos, J. K. Kaldellis, J.E. Garofalakis and I.P Koronaki : Interrelations of UV-global/global/diffuse solar irradiance components and UV-global attenuation on air pollution episode days in Athens, Greece. Atmospheric Environment 36, 2002, 3173-3181.

[9] M.H. Korany and H.A.Basset: The global and UV-radiation over Egypt. Atmosphere 20 (4), 2007, 341-358.

[10] Fioletov, V. E., J.B. Kerr and D.I. Wardle: The relationship between total ozone and spectral UV irradiance from Brewer spectrophotometer observations and its use for derivation of total ozone from UV measurements. J. Geophys. Res. Lett., 24, 1997, 2705-2708.

[11] Frederick, J.E., A.E. Koob, A.D. Alberts and E.C, Weatherhead: Emperical studies of tropospheric transmission in the ultraviolet: broadband measurements. J. Applied Meteo. ,32, 1993, 1883-1892.

[12] Herman, J.R., P.K. Brahma, J. Ziembke, Z. Ahmad and D. Larks: UV-B increases (1979-1992) from decreases in total ozone. Geophys, Res. Lett., 23, 1996, 2117-2120.

[13]Frederick, J.E. and H.E. Snell: Tropospheric influence on solar ultraviolet radiation: the role of clouds. J. Clim., 3, 1990, 373-381.

[14]Zaki Al-mostafa, Hamdy k. Elminir, Ahmed Abulwfa, Saad M. Al-shehri, Fawaz A. Alshehri, Ibrahim M. Al-Rougy, Ahmed A. Bazyad., Evaluation of erythemal ultraviolet solar radiation over Saudi Arabia. Solar Energy, 113, 2015, 258-271. 
[15] Samy A. Khalil, A. M. Shaffie. The relationship between total solar radiation and biologically erythematic radiation over urban region of Egypt., Renewable and sustainable energy reviews 38,2014, 1092-1099.

[16] Samy A. Khalil, A. M. Shaffie, Attenuation of the solar energy by aerosol particles: A review and case study, Renewable and Sustainable Energy Reviews 54, 2016, 363-375.

[17] Samy A. Khalil, A. M. Shaffie A comparative study of total, direct and diffuse solar irradiance by using different models on horizontal and inclined surfaces for Cairo, Egypt. Renewable and Sustainable Energy Reviews 27, 2013, 853-863

[18] Samy A. Khalil, A. M. Shaffie, Attenuation of the solar energy by aerosol particles: A review and case study, Renewable and Sustainable Energy Reviews 54,2016, 363-375.

[19] Samy A khalil, A. M. Shaffie and H. A. S. Aly, Comparative and Evaluate of Empirical Models for Estimation Global Solar Radiation in Al-Baha, KSA, Journal of earth science \& climatic change, 2018, 9.9.

[20] Samy A. Khalil, A. M. Shaffie, Hassan G. El Gohary, Faiz. M. B. Elshafia, A. A. ahmoud, Statistical Evaluation of Potential Solar Energy for Al-Baha location, Saudi Arabia, Albaha University Journal of Basic and Applied Sciences3(1), 2019,7-20

[21] Madronich, S.: Implications of recent total atmospheric ozone measurements for biologically active ultraviolet radiation reaching the Earth's surface. J. Geophys. Res. Lett., 19, 1992, 37-40.

[22] Madronich, S. and S. Flocke: theoretical estimation of biologically UV radiation at the Earth's surface. In: Zerefos, C.S., A.F. Bais (Eds.), Solar ultraviolet radiation modeling, Measurements and Effects, Vol. 52. NATOASI Series, Springer, Berlin, 1997, 23-48.

[23] Webb AR, Who, what, where and when influences on cutaneous vitamin D synthesis. Progress in Biophysics and Molecular Biology 92 (1), 2006, 17-25.

[24] McKinlay AF, Diffey BL, A reference action spectrum for ultraviolet induced erythemal in human skin. CIE-Hirek 6,1987, 17-22.

[25] Som AK, Solar UV-B radiation measurements over Bahrain. Renewable Energy 2 (1), 1992, 93-98.

[26] Robaa SM, A study of ultraviolet solar radiation at Cairo urban area, Egypt. Solar Energy 77, 2004, 251259.

[27] Sabziparvar AA, Shine KP, Forster PM de F, A model-derived global climatology of UV irradiation at the Earth's surface. J Photochem and Photobiol 69(2), 1999, 193-202.

[28] Al-Aruri SD, The empirical relationship between global radiation and global ultraviolet $(0.290-0.385) ? \mathrm{~m}$ solar radiation components. Sol Energy 45, 1990, 61-64.

[29] Elhadidy MA, Abdel-Nabi DY, Kruss PD, Ultraviolet solar radiation at Dhahran, Saudi Arabia. Sol Energy 44, 1990, 315-319.

[30] Sadler GW, Ultraviolet radiation at Edmonton, Alberta, Canada. Sol Energy 49,1992, 13-17.

[31] Mujahid AM, Correlation between ultraviolet radiation and global radiation in Riyadh, Saudi Arabia. Journal of Solar Energy Engineering Transactions of the ASME/116 1,1994,63-66.

[32] Martinez-Lozano JA, Casanovas AJ, Utrillas MP, Comparison of global ultraviolet (290-385 nm) and global irradiation measured during the warm season in Valencia, Spain. Int J Climatol 14, 1994, 93-102.

[33] Martinez-Lozano JA, Tena F, Utrillas MP, Ratio of UV to global broad band irradiation in Valencia, Spain. Int J Climatol 19, 1999, 903-911.

[34] Foyo-Moreno I, Vida J, Alados-Arboledas L, Ground based ultraviolet (290-385 nm) and broadband solar radiation measurements in south-eastern Spain. Int J Climatol 18, 1998, 1389-1400.

[35] Foyo-Moreno I, Vida J, Alados-Arboledas L, A simple all weather model to estimate` ultraviolet solar radiation (290-385 nm). J Appl Meteorol., 38, 1998, 1020-1025.

[36] Trabea AA, Salem AI, Empirical relationship for ultraviolet solar radiation over Egypt, Egypt J. Sol. Energy, 24, 2001, 123-32.

[37] De La Casinière A, Toure? ML, Masserot D, Cabot T, Pinedo Vega JL, Daily doses of biologically active UV radiation retrieved from commonly available parameters. Photochem and Photobiol 76, 2, 2002, 171175.

[38] Sabziparvar A., An improved estimation of daily clear-sky biologically EER from broadband global solar radiation, Inter. J. biometeorol, 53, 2009, 239-245.

[39]Lindfors A. Vuilleumier L., Ryythemal UV at Davos (Switzerland), 1926-2003, estimated using total ozone sunshine duration, and snow depth. J Geophy Res. D: Atmospheres 110, 2007, 1-15.

[40] Webb A, Steven MD, Daily total of solar UV-B radiation estimated from routine meteorological measurements. J Climatol 6, 1986, 405-411. 
[41] Ogunjobi KO, Kim YJ., Ultraviolet, (0.280-0.400 mm) and broadband solar hourly radiation at Kwangju, South Korea: analysis of their correlation with aerosol optical depth and clearness index. Atmos. Res. 71, 2004, 193-214.

[42] Samy A. Khalil, R.H.Hamid and M. Shaltout, Prediction of global solar radiation and investigation of climatic parameters for Halaib-Shalatin, Egypt, NRIAG, Journal of Astronomy and Astrophysics, Special issue, 2008, pp. 495-509.

[43] J. A. Duffie and W.A. Beckman, Solar Engineering of thermal Processes, 2nd Edn. John Wiley, New York, 1994, 167.

[44]El-Nashar, A. M., Solar radiation characteristics in ABU DHABI, Solar Energy, 1991, 47, $49 ? 55$.

[45] M. El-Nouby Adam, effect of the atmosphere on UV-B radiation reaching the earth's surface: dependence on solar zenith angle, Atmospheric and Oceanic science letter, Vol. 4, no 3, 2011 139-145.

[46] S.I.R.S.A. 1998, Manual de usuario, Sensor de radiación ultraviolet, modelo UV-B -1,sirsa@ sirsa.es.

[47] WMO, Report of the WMO meeting of experts on UV-B measurements, data quality and standardization of UV indices, Les Diablerets, Switzerland. 1994.

[48] McKinlay A.F. and Diffey B.L., A reference action spectrum for ultraviolet induced erytema in human skin, CIE Journal, 6, 1987, 17-22.

[49] Perez, R., Ineichen, P., Seals, R., Modeling daylight availability and irradiance components from direct and global irradiance. Solar Energy, 44, No. 5, 1990, 271-289.

[50] Anton, M., Serrano, A., Cancillo, M.L., Garcia, J.A., An empirical model to estimate ultraviolet erythemal transmissivity. Annales Geophysicae, 27, 2009, 1387-1398.

[51] Serrano, A., Anton, M., Cancillo, M.L., Garcia, J.A., Proposal of a new erythemal UV radiation amplification factor, Atmospheric Chemistry and Physics Discussion, 8, 2008, $1089 ? 1111$.

[52] M. Anton, A. Serrann, M. Cancillo, and J. A. Garica, An empirical model to estimate ultraviolet erythemal transmissivity. Annales Geophysicae, 27, 2009, 1387-1398.

[53] Kudish, A. I., et al.,: Intercomparison of the solar UV-B , UV-A and global radiation clearness and UV indices for Beer Sheva and Neve Zohar (Dead Sea), Israel, Energy, 30, 2005, 1623 ?1641.

[54] M., El-Nouby Adam, Effect of stratospheric Ozone in UV-B solar radiation reaching the Earth's surface at Qena, Egypt, Atmospheric Pollution Research, 1, 2010, 155-160.

[55] Krzyscin JW, Jaroslawski J, Sobolewski PS, Effects of clouds on the surface erythemal UV-B irradiance at northern midlatitudes: estimation from the observations taken at Belski, Poland (1999 - 2001). J Atmos. Sol.-Terr. Phys. 65, 2003, 457-467

[56] Canada J, Pedros G, Bosca JV, Relationships between UV (0.290-0.385mm) and broadband solar radiation hourly values in Valencia and Cordoba, Spain. Energy 28, 2003, 199-217.

[57]Zerefos C, Balis D, Tzortziou M, Bais A, Tourpail K, Meleti C, Bernhard G, Herman J, A note on the interannual variations of UV-B erythemal doses and solar irradiance from ground-based and satellite observations. Annales Geophysicae 19, 1, 2001, 115-120.

[58] Sabziparvar A, and Shetaee H, Estimation of global solar radiation in arid and semi-arid climates of East and West Iran. Energy 32, 5, 2007, 649-655.

[59]Dentener and Crutzen .Reaction of N2O5 on tropospheric aerosols: Impact on the global distributions of NOx, O3, and OH. Journal of Geophysical Research Atmospheres 98(D4) April 1993.

[60] Prospero, Ginour, Torres, Chin. Long-term simulation of global dust distribution with the GOCART model: correlation with North Atlantic oscillation. Environmental Modeling \& Software, 19 2004, 113-128.

[61]Dentener, Gregory, cormical, Jose and Crutzen. Role of mineral aerosol as areactive surface in the global troposphere, Journal of Geophysical Research, val. 101, No. D17, 1996 22,869-22,889.

Citation: Samy A. Khalil,et.al.," Prediction of Doses Biologically Active Ultraviolet Solar Radiation from Measurements of Global Solar Radiation", International Journal of Research in Environmental Science (IJRES), vol. 6, no. 2, pp. 30-41, 2020. Available: DOI: http://dx.doi.org/10.20431 /2454-9444.0602004

Copyright: (C) 2020 Authors. This is an open-access article distributed under the terms of the Creative Commons Attribution License, which permits unrestricted use, distribution, and reproduction in any medium, provided the original author and source are credited. 